\title{
Compact microstrip bandpass filter with tunable notch
}

\author{
Christensen, Silas; Zhurbenko, Vitaliy; Johansen, Tom Keinicke
}

Published in:

Proceedings of 2014 20th International Conference on Microwaves, Radar, and Wireless Communications

Link to article, DOI:

10.1109/MIKON.2014.6899837

Publication date:

2014

Link back to DTU Orbit

Citation (APA):

Christensen, S., Zhurbenko, V., \& Johansen, T. K. (2014). Compact microstrip bandpass filter with tunable notch. In Proceedings of 2014 20th International Conference on Microwaves, Radar, and Wireless Communications IEEE. https://doi.org/10.1109/MIKON.2014.6899837

\section{General rights}

Copyright and moral rights for the publications made accessible in the public portal are retained by the authors and/or other copyright owners and it is a condition of accessing publications that users recognise and abide by the legal requirements associated with these rights.

- Users may download and print one copy of any publication from the public portal for the purpose of private study or research.

- You may not further distribute the material or use it for any profit-making activity or commercial gain

- You may freely distribute the URL identifying the publication in the public portal 


\title{
Compact Microstrip Bandpass Filter with Tunable Notch
}

\author{
Silas Christensen ${ }^{1}$, Vitaliy Zhurbenko ${ }^{2}$ and Tom K. Johansen ${ }^{3}$ \\ Technical University of Denmark, DTU - Department of Electrical Engineering, DK-2800 Kgs. Lyngby, Denmark \\ E-mails: ${ }^{1}$ silas@alumni.dtu.dk , ${ }^{2}$ vz@elektro.dtu.dk and ${ }^{3}$ tkj@elektro.dtu.dk
}

\begin{abstract}
Two different designs combining a bandpass and a notch filter are developed to operate in the receiving band from 350-470 MHz. The bandpass filter is designed from a simple structure, by use of only four short circuited stubs and a half wavelength transmission line connecting the stubs. The tunable notch filter ensures an attenuation level of $19.3 \mathrm{~dB}$ to $27.3 \mathrm{~dB}$ in the frequency range from 360-480 $\mathrm{MHz}$. The measured passband ripple of the combined filter is less than $0.5 \mathrm{~dB}$, while the insertion loss for the simplest design is less than $1.7 \mathrm{~dB}$ only $10 \mathrm{MHz}$ from the notch frequency. Even though the wavelength on the selected substrate $\left(\epsilon_{r}=3.55\right)$ is approximately $45 \mathrm{~cm}$, the outer dimensions of the final filter only measure $10 \times 10 \mathrm{~cm}^{2}$.
\end{abstract}

\section{INTRODUCTION}

Wireless systems has during the past generations increased rapidly, which has resulted in a fully covered frequency spectrum for the range that most of today's technologies can handle. However may the spectrum not be reserved for the same application around the globe and therefore is it not guaranteed that a product developed for one country, can be implemented elsewhere. This has increased the interest of tunable or reconfigurable filters [1], with the possibility to change the receiving band or filter out unwanted transmissions at different frequencies. This paper covers the development of a tunable notch filter, fully integrated in the structure of a bandpass-filter covering the band from 350 to $470 \mathrm{MHz}$. The main challenge has been to find an optimum method for coupling the notch filter into the bandpass filter, without affecting the individual properties significantly. The purpose of the notch filter was originally intended to filter out the transceivers own transmitted signal [2], in order to protect the receiver from saturation, but may, as described above, also be very useful for other applications.

Initially a description and design procedure of the chosen bandpass configuration, [3], is presented in Section II. Following in Section III is a short resume of the different design considerations that have been taken into account in order to find the optimum configuration for the notch filter. With the design procedure for the two individual filter types in place, two different combination possibilities are introduced in Section IV along with the results for both simulations and the actual measurements of two different prototypes, which do match very well, as seen in Section V. Finally is a conclusion drawn in Section VI.

\section{BAND-PASS FILTER CONFIGURATION}

The bandpass filter was designed based on the configuration presented in [3] and shown in Figure 1. The filter may be

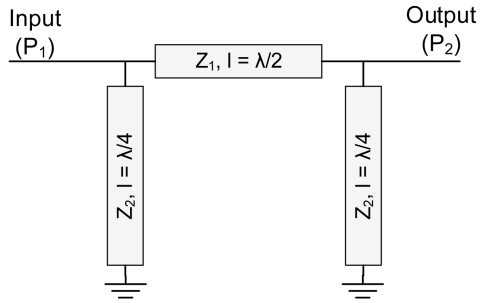

Fig. 1. Diagram of the wideband band-pass filter configuration, consisting of two short circuited stubs with the dominant half wavelength center line in between.

designed to have three reflection zeros, as seen from the simulation results in Figure 2, if a proper impedance ratio between the lines is chosen. The center reflection zero is dominated by the half wavelength center line, while the position of the two symmetric poles can be determined by [3]

$$
\begin{gathered}
f_{1}=\frac{1}{\pi} \arctan \sqrt{\frac{\left(1+\frac{z_{1 n}}{z_{2 n}}\right) \frac{z_{1 n}}{z_{2 n}}}{\left(1+\frac{z_{1 n}}{z_{2 n}}\right)-z_{1 n}^{2}},} \\
f_{2}=\frac{1}{\pi}\left[\pi-\arctan \sqrt{\frac{\left(1+\frac{z_{1 n}}{z_{2 n}}\right) \frac{z_{1 n}}{z_{2 n}}}{\left(1+\frac{z_{1 n}}{z_{2 n}}\right)-z_{1 n}^{2}}}\right],
\end{gathered}
$$

where $f_{1}$ and $f_{2}$ er normalised to $f_{0}$, while $z_{1 n}$ and $z_{2 n}$ are the normalised line impedances. A condition for obtaining the three zeros is that, $z_{2 n}$ must be kept below $z_{1 n} /\left(z_{1 n}^{2}-1\right)$. The

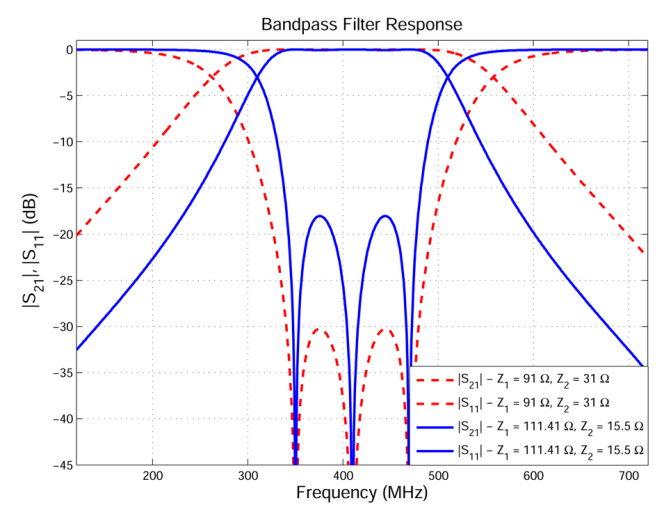

Fig. 2. Simulation results for the bandpass filter with two different equivalent impedance ratios. The obtained $3 \mathrm{~dB}$ bandwidth is $48.8 \%$, which exceeds the original requirement, however was this not weighted so high. The main focus has been the combination of the notch and bandpass filter. 
design was originally intended for ultra wideband application, while the desired bandwidth from $350-470 \mathrm{MHz}(30 \%)$ is relatively low compared to the ones obtained in [3]. This means that the impedance ratio becomes quite high in order to ensure the correct bandwidth and an acceptable out-of-band slope. Initially was $z_{2 n}$ selected to 0.62 , which for a $50 \Omega$ system led to

$$
\mathrm{Z}_{2} \approx 31 \Omega \text { and } \mathrm{Z}_{1} \approx 91 \Omega
$$

where both impedances are realisable in a microstrip process. However, as seen in Figure 2, does this ratio not result in such an attractive response, so a higher ratio is required. In order to realise impedances below $20-30 \Omega$, the idea to use two s.c. stubs in shunt, on each side of the center line, was introduced. This shunt configuration results in the equivalent impedance for $\mathrm{Z}_{2}$ of $15.5 \Omega\left(z_{2 n}=0.31\right)$, which leads to

$$
z_{1 n}=2.23 \Rightarrow \mathrm{Z}_{1} \approx 111.41 \Omega \text {. }
$$

With these, still realisable, impedances was the passband narrowed and the slope became steeper. The price is of course the increased physical size, but also a degraded return loss, although still kept better than $18 \mathrm{~dB}$ across the entire passband.

\section{NOTCH FILTER DESIGN}

The main concept used for the development of the notch filter is based on the shunted RLC-resonator, which also has been the underlying basis for the work presented in [4] and [5]. The series RLC-resonator will have the desired bandstop filter response, which may be obtained from a $\lambda / 4$ microstrip stub-resonator, as the one shown in Figure $3 a,[4]^{1}$. The capacitor $C_{3}$ is used to tune the total electrical length of the resonator, since it will extend the equivalent length of the stub. Simulations of the configuration (Figure 3a) further indicates that a higher quality factor of the resonator must be obtained. This could be obtained by use of

$$
l_{\text {elec }, \text { tot }}=90^{\circ}+180 \cdot n, \quad n=0,1,2, \ldots,
$$

which does give an improved notch, but also increases the loss of the system. An alternative is capacitive coupling of the resonator, which is a common approach for increasing the quality factor of the resonator, [6]. The advantages of these two method are used in [5] (see Figure 3b), where the line length naturally is increased due to the fact that at capacitively coupled parallel resonator (which must be of minimum $\lambda / 2$ ), will be transformed to a series resonator [6], [7].

In [4] the stub is used to generate a passband and represents therefore a parallel resonator. The bandwidth of the parallel resonator may be tuned with $C_{1}$, since the $\mathrm{Q}$ will increase with $C_{1}$. For the series resonator the change in the stopband will unfortunately not be affected in the same proper way, which has been proven by simulations, but is not presented in

${ }^{1}$ In [4] is the configuration used to obtain a passband, where the microstrip line instead represent a parallel RLC-resonator with a length of $\lambda / 2$ or eletrically $180^{\circ}$

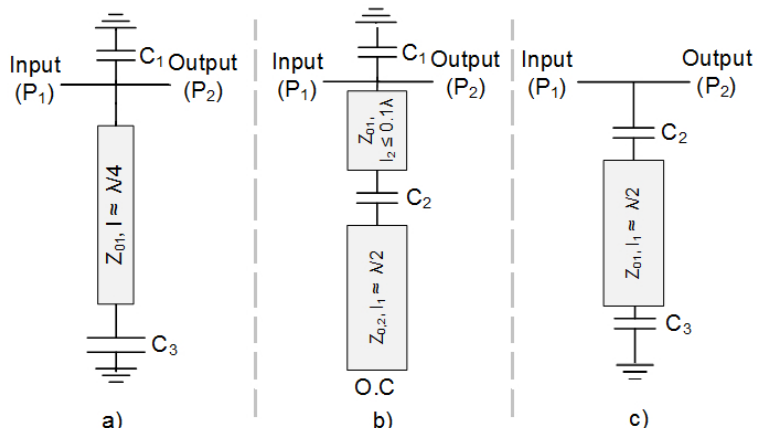

Fig. 3. Three different notch configurations. a) Tunable parallel resonator, b) Capacitive coupled series resonator c) Capacitive coupled tunable series resonator.

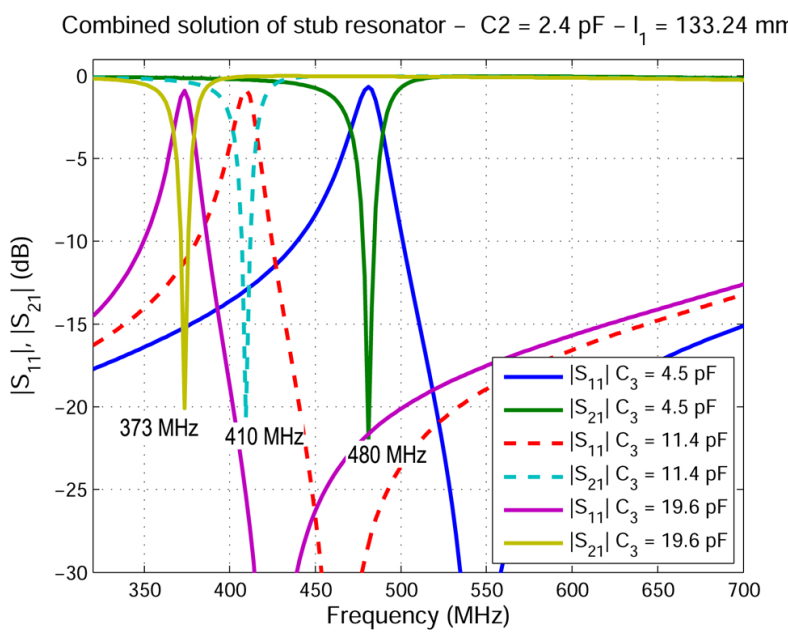

Fig. 4. Simulated response of the notch filter.

this paper. Hence $\mathrm{C}_{1}$ is not useful for the application of this paper and therefore neglected. Taking advantages of the useful properties of the two configuration of Figure $3 a$ and $b$, led to the configuration shown in Figure 3c.

The filter response for different values of $\mathrm{C}_{3}$ is shown in Figure 4, where most of the band of interest is covered by use of a single tuning capacitor ${ }^{2}$, with an attenuation of at least $20 \mathrm{~dB}$ for all of the frequencies.

\section{A. The bended microstrip resonator}

The simulation results shown in Figure 4, indicates that the insertion loss at frequencies below the notch should be improved. The bended $\lambda / 4$-microstrip resonator described in [5] was found interesting, since the results presented showed a possible sharper edge, than what is obtained with use of the previous presented filter configurations. The design is shown in Figure 5a, where the total length of the coupled line must represent a quarter wavelength. This configuration was further found interesting for the following two reasons. The first, is that the physical implementation can become more compact, since $l_{2}$ can be folded, while there is no need for a whole

\footnotetext{
${ }^{2}$ The range of the tunable capacitor used, JZ200, is going from $4.5 \mathrm{pF}$ to $20 \mathrm{pF}$.
} 


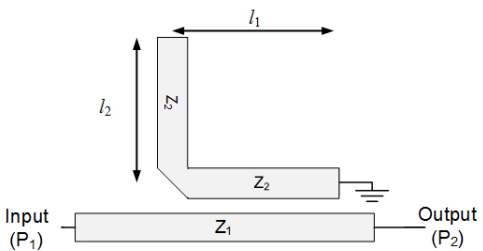

a)

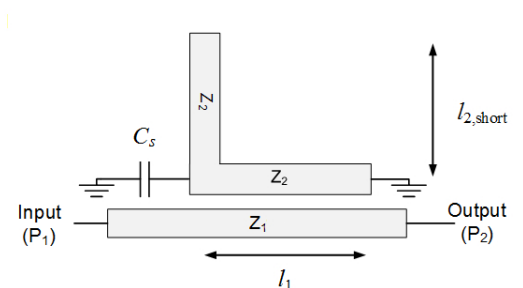

b)

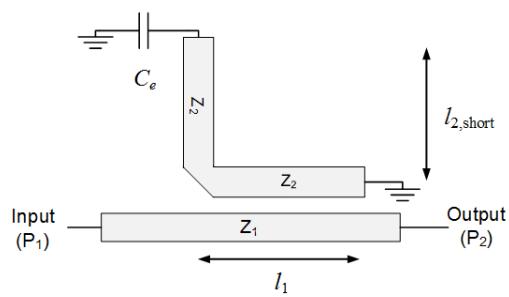

c)

Fig. 5. a) Bended resonator, b) with tuning capacitor at the side, or c) at the end of the microstrip resonator.

quarter wavelength between Port 1 and $2^{3}$. Secondly, the bandwidth of the notch can be controlled by varying the length of $l_{1}$ or the distance between the mainline and the resonator ${ }^{4}$. Thus this will affect the amount of energy coupled to the resonator and thereby the depth of the attenuation. Instead of using $50 \Omega$-lines in the coupling configuration, the design parameters for a $10 \mathrm{~dB}$ coupler was found to be a good outline for the coupled resonator.

The model presented in [5] do only support a single frequency, but by combining the concepts of the previous presented configurations, the two models shown in Figure 5b and $\mathrm{c}$ was developed. Common for both capacitors is that they will extend the electrical length of the resonator, and therefore the length of $l_{2}$ must be reduced as the capacitor size is increased. In order to obtain the same resonance the admittance of the configuration with $C_{s}$ (Figure 5b) must equal the one of the O.C. line without the capacitor, leading to

$$
j \mathrm{Y}_{2} \tan \left(\beta \mathrm{l}_{2}\right)=j \mathrm{Y}_{2} \tan \left(\beta l_{2, \text { short }, s}\right)+j \omega C_{s},
$$

where $l_{2}$ will be fixed, $\beta$ is determined from the effective

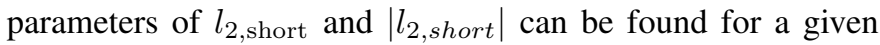
size of $C_{s}$. Similar for the configuration with the capacitor at the end of the line, an expression for the impedances can be written as

$$
\begin{gathered}
-j \mathrm{Z}_{2} \cot \left(\beta \mathrm{l}_{2}\right)=\mathrm{Z}_{2} \frac{Z_{L}+j \mathrm{Z}_{2} \tan \left(\beta l_{2, \text { short }, e}\right)}{\mathrm{Z}_{2}+j Z_{L} \tan \left(\beta l_{2, \text { short }, e}\right)}, \\
\text { where } \quad Z_{L}=\frac{1}{j \omega C_{e}} .
\end{gathered}
$$

From simulations of different ratios between the two parts $\left(l_{1}\right.$ and $l_{2}$ ) of the resonator in Figure 5a, the optimum length for $l_{1}$ was found to be $25 \mathrm{~mm}$, in order to obtain an acceptable attenuation level and slope at the edge of the notch. Combining this length with (3) and (4) and a capacitor value of $4.5 \mathrm{pF}$ led to the dimensions shown in the top of Figure 6, for resonance at $480 \mathrm{MHz}$. The simulation results for both configurations are shown in the figure, with different values of the tuning capacitor. The attenuation falls of as the capacitance increases and the resonance frequency decreases. This must be related to the fact that the microstrip line becomes electrically smaller

\footnotetext{
${ }^{3}$ This would be the case for an standard coupled line resonator, which is also presented in [5].

${ }^{4}$ This is comparable to changing the size of $C_{2}$ in Figure $3 \mathrm{c}$.
}

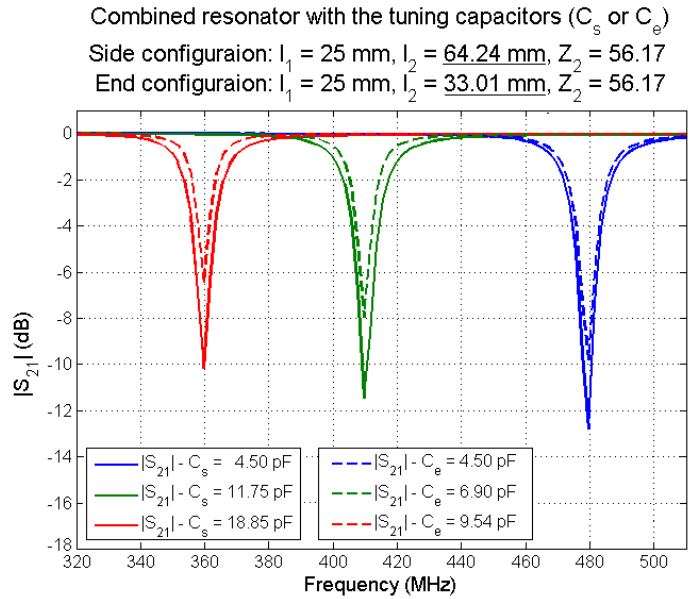

Fig. 6. Simulation of combined designs with different capacitor value for the capacitors at either the side (s) or the end (e) of the microstrip resonator.

and the $\mathrm{Q}$ of the capacitor becomes more dominant $\left(\mathrm{Q}_{\text {cap }} \approx\right.$ $200, \mathrm{JZ200}$ ). The configuration with $C_{e}$ is very sensitive to the variation and the attenuation is lower, which complies with the hypothesises of the effect of the line length, since $l_{2, \text { short,e }}$ is only half the length of $l_{2, \text { short,s }}$. The minimum attenuation of $10.2 \mathrm{~dB}$ and the lower sensitivity is the reason why the configuration of Figure $5 \mathrm{~b}$ is used in the final design. For the combined filter was two cascaded resonators implemented, in order to ensure an attenuation level greater than $15 \mathrm{~dB}$.

\section{COMBINED FILTER}

Two different design combinations were carried out, one where the two filter types simply are cascaded (Figure 7a) and one where the notch filter is directly coupled to the center line of the bandpass filter (Figure 7b). For the cascaded filter the configurations already presented could directly be reused. For the integrated configuration was the coupler designed with the center line of the bandpass filter, as the through line. The coupling was then optimised to obtain the same amount, as for the initially outlined notch filter ${ }^{5}$.

As mentioned were two resonators implemented to obtain the desired attenuation level, and the separation distance between the two resonators is very significant wrt. the reflection coefficient of the filter. The optimum separation distances

\footnotetext{
${ }^{5}$ The minimum width of $l_{2}$ was selected to $1.4 \mathrm{~mm}$, due to the minimum required soldering pad for the tunable capacitor JZ200.
} 
TABLE I

MEASURED RESUlTS. THE NUMBERS IN THE PARENTHESES IS THE DIFFERENCE FROM THE RESULTS OF THE CO-SIMULATION.

\begin{tabular}{|c|c|c|c|c|}
\hline \multirow[b]{2}{*}{ Frequency } & \multicolumn{2}{|c|}{ Cascaded design } & \multicolumn{2}{|c|}{ Integrated design } \\
\hline & Notch Attenuation & Insertion loss @ -10 MHz & Notch Attenuation & Insertion loss @ -10 MHz \\
\hline $361 \mathrm{MHz}$ & $19.41 \mathrm{~dB}(+1.69)$ & $0.95 \mathrm{~dB}(+0.15)$ & $19.35 \mathrm{~dB}(+1.93)$ & $2.60 \mathrm{~dB}(+0.66)$ \\
\hline $422 \mathrm{MHz}$ & $26.72 \mathrm{~dB}(+2.57)$ & $1.03 \mathrm{~dB}(-0.15)$ & $19.17 \mathrm{~dB}(-6.64)$ & $2.05 \mathrm{~dB}(-0.37)$ \\
\hline $480 \mathrm{MHz}$ & $27.29 \mathrm{~dB}(+0.27)$ & $1.60 \mathrm{~dB}(-0.33)$ & $23.52 \mathrm{~dB}(-11.9)$ & $2.38 \mathrm{~dB}(-0.83)$ \\
\hline & Relative & Normalized $\left(f_{c}=427.6 \mathrm{MHz}\right)$ & Relative & Normalized $\left(f_{c}=415.8 \mathrm{MHz}\right)$ \\
\hline$-3 \mathrm{~dB}$ Bandwidth & $193.6 \mathrm{MHz}(+0.3 \mathrm{MHz})$ & $46.58 \%(-0.65 \%)$ & $219.7 \mathrm{MHz}(-1.1 \mathrm{MHz})$ & $51.39 \%(+0.09 \%)$ \\
\hline
\end{tabular}

are different for the two models, and is easiest found by simulations of only the two cascaded resonators.

For the layout of the bandpass filter, the idea of having the s.c. stubs connected at the same ground vias, is inspired by the work presented in [8]. The internal path was simply compressed as much as possible, while still keeping a conservative distance between the lines $(\approx 10 \mathrm{~mm})$, to avoid any possible coupling. This conservative choice means that, even though the outer dimensions of the integrated configuration only measure $10 \mathrm{~cm} \times 10 \mathrm{~cm}$, they might still be reduced.

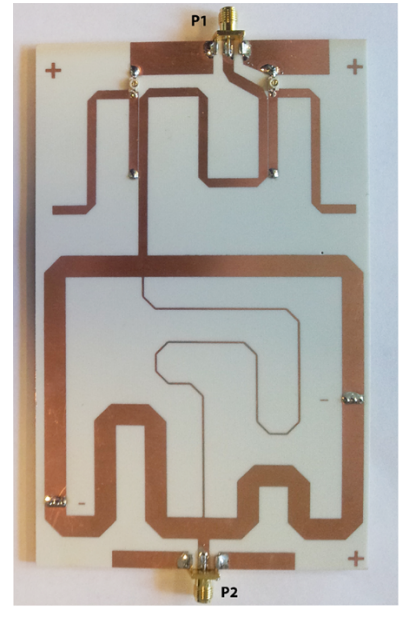

a)

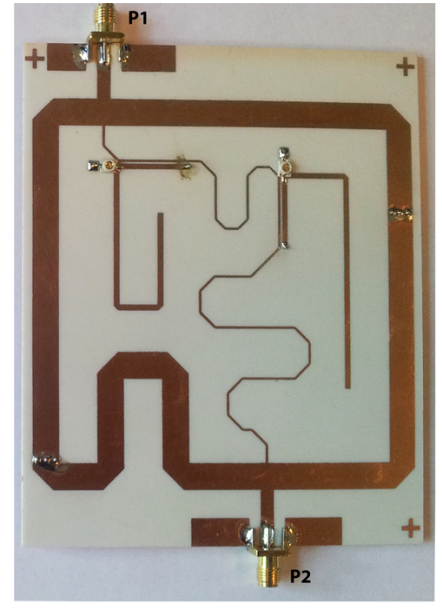

b)
Fig. 7. Prototypes: a) Cascaded design and b) Integrated design.

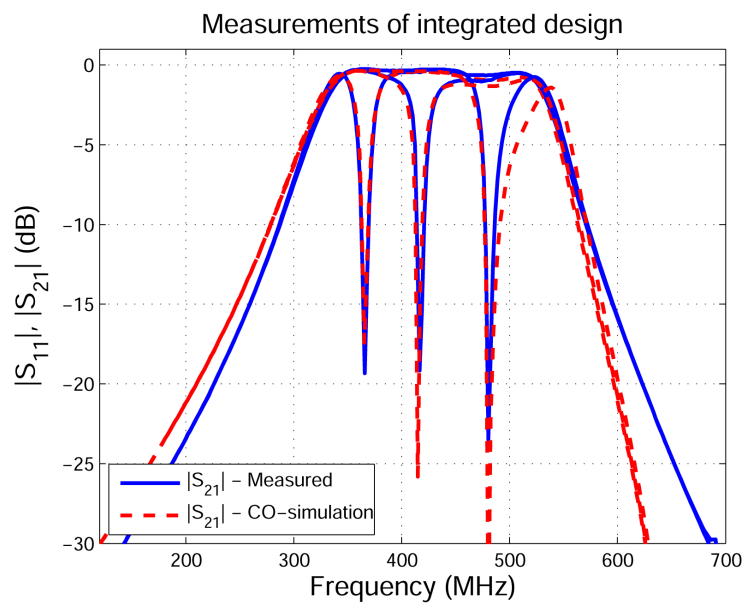

Fig. 8. Measured and CO-simulated results for the integrated design.

\section{RESUlts}

Initially were both filters worked out by use of the standard circuit models in ADS and compared with a CO-simulation model, were no greater differences were observed. This was expected due high precision of the circuit models at the relatively low operating frequency. Comparison between the measured results and the CO-simulations shows fine agreement. This is seen graphically for the integrated design in Figure 8 and numerically for both models in Table I. The very high attenuation levels of the CO-simulation might be related to some calculated infinite zeros, which are not obtainable in a real life scenario. In relation to the losses has the simulation models probably been to idealised with a too high conductivity, which also is directly related to the $\mathrm{Q}$ factor of the resonators. The overall $-3 \mathrm{~dB} \mathrm{BW}$ is affected by the combination of the two filters types, but the changes is only within $\pm 2.6 \%$ for both configurations wrt. to the ideal filter described in Section II.

\section{CONCLUSION}

A design procedure for combining a passband filter with a tunable notch is presented. The basic blocks are derived by use of analytical calculations, but simulation tools are essential to finalise the complete configuration. Measurements shows that an attenuation level of at least $19.3 \mathrm{~dB}$ is obtained in the tunable range from $360-480 \mathrm{MHz}$. The integration of the two filters is not without consequences, since the $-3 \mathrm{~dB}$ bandwidth is increased and the notch attenuation is lowered. However are handles for optimising the different specification of the individual and combined filters provided in this paper.

\section{REFERENCES}

[1] J. sheng Hong, "Reconfigurable planar filters," IEEE Microwave Magazine, vol. 10, no. 6, pp. 73-83, 2009.

[2] O. Oletuegbe, "A distributed tunable filter design for tetra systems," Master's thesis, DTU - Department of Electrical Engineering, 2013.

[3] C.-W. Tang and M.-G. Chen, "A microstrip ultra-wideband bandpass filter with cascaded broadband bandpass and bandstop filters," IEEE Transactions on Microwave Theory and Techniques, vol. 55, no. 11, pp. 2412-2418, 2007.

[4] J. M. Drozd and W. T. Joines, "A capacitively loaded half-wavelength tapped-stub resonator," IEEE Transactions on Microwave Theory and Techniques, vol. 45, no. 7, p. 1100, 1997.

[5] K. Rambabu, M.-W. Chia, K. M. Chan, and J. Bornemann, "Design of multiple-stopband filters for interference suppression in uwb applications," IEEE Transactions on Microwave Theory and Techniques, vol. 54, no. 8, pp. 3333-3338, 2006.

[6] P. A. Rizzi, "Microwave engineering: passive circuits," 1988.

[7] D. M. Pozar, Microwave Engineering, 3rd ed. John Wiley and Sons, 2005.

[8] K. Rabbi, L. Athukorala, and D. Budimir, "High linearity microstrip bandpass filter with electronically tunable notch," Microwave and Optical Technology Letters, vol. 55, no. 2, pp. 418-421, 2013. 